\title{
Features of a Good Story for Non-Technical Adults to Learn Emerging Technologies
}

\author{
https://doi.org/10.3991/ijet.v15i03.11645 \\ Keisuke Seya $(\bowtie)$, Nobuyuki Kobayashi, Seiko Shirasaka \\ Keio University, Kanagawa, Japan \\ keisuke.seya@keio.jp
}

\begin{abstract}
The need to learn emerging technologies such as artificial intelligence is increasingly important not only for technical people but also for nontechnical people. Previous studies showed the effectiveness of a story-based teaching method for both technical and non-technical people who want to learn emerging technologies. However, the difference between the story-building methods for technical people and non-technical people has not been revealed. The purpose of this research is to propose perspectives that reveal the differences in the stories used for emerging technology education and identify the effective story features suited for non-technical adult learners by comparing the different story-building methods used for technical people and non-technical people. In this study we classified the story types into two perspectives: "past to present" and "present to future" and compared the two story-building methods in these perspectives. The novelty of this research is that the proposal of perspectives that reveal the differences in the stories used for emerging technology education and that we have identified the features of one of the effective stories suited for nontechnical adult learners. We also examined the possibility of leveraging such differences in solving the issues that a class of non-technical people called conversational programmers is facing.
\end{abstract}

Keywords-Technical Education, Adult Learners, Story, Teaching Method, Artificial Intelligence, Conversational Programmers

\section{Introduction}

Emerging technologies such as artificial intelligence penetrate rapidly into our lives [1], and it is urgently necessary not only to foster specialists who can cope with those technologies but also provide the basics of such technologies for non-technical adults who graduated from school many years ago. In fact, recent studies revealed the existence of conversational programmers [2], [3] who are willing to learn programming to make themselves knowledgeable enough to participate in technical conversations even though they do not write programs by themselves in their job role. It is known that conversational programmers exist widely in various industry sectors and job roles [4]. Just recently we begin to see artificial intelligence online courses for business professionals [5], [6], [7] but these are not for the conversational programmers because their 
focus is to teach enough about artificial intelligence for the learners to navigate a business and they don't provide some level of programming experience to the learners.

Under such circumstances, in emerging technology education where it is necessary to learn multiple technologies in a complex manner, the effectiveness of the story-based teaching method for both technical and non-technical people is confirmed [8], [9]. However, the difference between the two stories was not identified.

The purpose of this research is to propose perspectives that reveal the differences in the stories used for emerging technology education and identify the effective story features suited for non-technical adult learners by comparing the different story-building methods used for technical people and non-technical people. We propose to categorize the story types from the two perspectives: "past to present" and "present to future" and compare the story-building methods in these perspectives. Here, a story with the "past to present" perspective is a story that provides the chronological or logical connection between the learning topics. A story with the "present to future" perspective refers to a story that expects the learners to be capable of dealing with not only the present problems but also the unknown future problems.

To make the comparison possible, we first clarified each story-building procedure in two different story types and compared the two procedures. As a result of the comparison, we found that there is a difference in the size of the learning space and the reason why it is not always possible to select chronologically and logically related learning topics in the stories constructed from a "present to future" perspective. Furthermore, in addition to the obvious differences between the two story-building procedures, we found implicit differences arisen from the difference in each story context even though the description of the procedures is exactly the same.

The above difference between the two studies is the new information which cannot be found in a single study but found only when the two studies are compared [10]. Therefore, the novelty of this research is that the proposal of perspectives that reveal the differences in the stories used for emerging technology education and that we have identified the effective story features suited for non-technical adult learners. We also examined the possibility of leveraging of such differences in solving the issues that non-technical people called the conversational programmers are facing.

The remainder of this paper is organized as follows. Chapter 2 presents related works. Chapter 3 describes the research method. Chapter 4 presents the result. Chapter 5 evaluate the result. Chapter 6 discusses the result and evaluation. Chapter 7 provides the conclusion and future research topics.

\section{Related Works}

The educational theories have long been studied by researchers from various perspectives [11] including a perspective of teaching adults such as andragogy [12]. Since such theories have been validated in a traditional learning context, some researchers try to adopt or extend them in the information age context with the use of new technologies and tools available in learning [13]. There are several studies about the use of new 
technologies to teach adults effectively [14], [15], [16] but these studies are not about how to teach new technologies to adult learners.

Other efforts to provide effective education includes but not limited to teaching strategies, methods, and models in combination with new technologies [17], [18], [19]. Some empirical studies in this context have been deployed to the adult learners and shown the effectiveness of their approaches [20]. Such results are encouraging but the features which led the study successful remain hidden because the studies cannot see their own features unless they have other studies to be compared.

Prior research aimed at fostering engineers of Cyber-Physical System (CPS) [8] showed the effectiveness of a story-based teaching method. In the research, instead of teaching the independent learning topics separately, by mapping the learning topics around a single story, the lecture successfully attracted the learners for they were allowed to implement the story in their way. However, the story-building method was not disclosed. Also, it did not clarify whether this teaching method works for non-technical adults.

On the other hand, Seya et al. found one of the effective story-based methods for non-technical adult learners to understand artificial intelligence [9]. Another research [21] clarified the general procedure to make the story of this kind and discussed if the story created by this procedure solves the issues that the conversational programmers are facing [4]. Also, the issues for technical people in completing online courses whose story is created from a "present to future" perspective are identified [22].

\section{Method}

The procedure of making a story from a "past to present" perspective was clarified by the previous research [21]. However, how to make a story from a "present to future" perspective is not clarified yet. Therefore, we first clarify the procedure of making a story of this kind. For this purpose, we will clarify the procedure of story-building method deployed in the study for CPS education [8] because such an education tries to train the learners not only to be capable of dealing with the present problems but also to be capable of dealing with the unknown future problems. Finally, we compare the two story-building methods $n$ multiple perspectives.

\section{Result}

\subsection{How to create a story from a "present to future" perspective}

Table 1 shows the procedure of making a story from a "present to future" perspective. The procedure from Step 1 to Step 5 is a design process that determines the frame of the story. The procedure from Step 6 to Step 10 is the implementation process that fills the concrete contents. 
Table 1. Story making procedure from a "present to future" perspective

\begin{tabular}{|c|c|}
\hline Steps & Descriptions \\
\hline Step 1 & Grasp an overall picture of technical topics in the field of the subject \\
\hline Step 2 & Set concrete learning goals \\
\hline Step 3 & $\begin{array}{l}\text { Identify main topics which are necessary for accomplishing the concrete learning goal, and } \\
\text { map them onto the parts of a story }\end{array}$ \\
\hline Step 4 & Identify sub-topics which are necessary for accomplishing the goals of main topics. \\
\hline Step 5 & Temporarily fix main topics and sub-topics as lecture blocks \\
\hline Step 6 & $\begin{array}{l}\text { Implement main topics. Try to implement the main topics allowing the learners to see multi- } \\
\text { ple approaches and different levels of abstraction to solve the problems. Try to implement a } \\
\text { sub-topic inside a closely related main lecture block unless the volume of the main lecture } \\
\text { block does not become too large }\end{array}$ \\
\hline Step 7 & Implement lectures for large sub-topics as independent lecture blocks \\
\hline Step 8 & $\begin{array}{l}\text { Implement both core learning tasks for all learners and advanced learning tasks for advanced } \\
\text { learners in each lecture block }\end{array}$ \\
\hline Step 9 & $\begin{array}{l}\text { Fix the lecture blocks if they are compatible with administrative constraints. Go back to Step } \\
3 \text { if it is necessary to meet the constraints }\end{array}$ \\
\hline Step 10 & $\begin{array}{l}\text { Place an introduction of the subject as the first lecture block and explain the whole picture of } \\
\text { the lecture in this block }\end{array}$ \\
\hline
\end{tabular}

\subsection{Result of creating a story from a "present to future" perspective for the lecture on CPS}

Following is the result of creating a story from a "present to future" perspective for the lecture on CPS. Figure 1 shows how technical topics are mapped to the story.

Step 1: Grasp an overall picture of technical topics in the field of CPS

Technical topics that need to be covered in the field of CPS:

Control, Sensor, Operation, Observe, Process, Data, Network

Step 2: Set concrete learning goals

Build a robot, which can move around autonomously and also is remotely controllable via Network. Collect image data and audio data from corresponding sensors. Monitor the status of the robot on a cloud server around the clock. Use the processed data on the cloud server to control the control system of the robot.

Step 3: Identify main topics which are necessary for accomplishing the concrete learning goal, and map them onto the parts of a story.

Identify main topics to be covered in the lecture:

Control, Sensor, Operation, Observe, Process, Data, Network 


\section{Map the main topics onto the concrete learning goals with a story:}

- Make legs to learn how to control motors (Control)

- Make eyes to learn how to process image data from the sensor (Sensor, Process, Data)

- Make a mouth to learn how to convert text data into the audio data (Process, Data)

- Make ears to learn how to process audio data (Sensor, Process, Data)

- Make a robot remotely controllable (Observe, Control, Network, Operation)

Step 4: Identify sub-topics which are necessary for accomplishing the goals of main topics

Sub-topics need to be covered in the lecture:

- How to set up a development environment

- How to write a program for the first time

- How to control hardware by software

Step 5: Temporarily fix main topics and sub-topics as lecture blocks.

Step 6: Implement the main topics. Try to implement the main topics allowing the learners to see multiple approaches and different levels of abstraction to solve the problems. Try to implement a sub-topic inside a closely related main lecture block unless the volume of the main lecture block does not become too large.

Step 7: Implement lectures for large sub-topics as independent lecture blocks.

Step 8: Implement learning tasks.

Step 9: After examining if lecture blocks are within time constraints, the lecture block for "How to set up a development environment" turned out to be too long. Go back to Step 3.

Step 3 (2nd round): No change needed for main topics.

Step 4 (2nd round): The sub-topic, "How to set up a development environment", is divided into two sub-topics: "How to set up the hardware" and "How to set up a standalone system environment".

Step 5: Change the flow of the sub-topic lecture blocks:

- How to set up the hardware

- How to write a program for the first time

- How to control hardware by software

- How to set up a stand-alone system environment

Step 6 (2nd round): No change needed.

Step 7 (2nd round): Implement lectures for the new sub-topics: "How to set up the hardware" and "How to set up a stand-alone system environment".

Step 8 (2nd round): No change needed.

Step 9 (2nd round): Fix the lecture blocks if they are compatible with administrative constraints. 
Step 10: Place an introduction of the subject as the first lecture block and explain the whole picture of the lecture in this block.

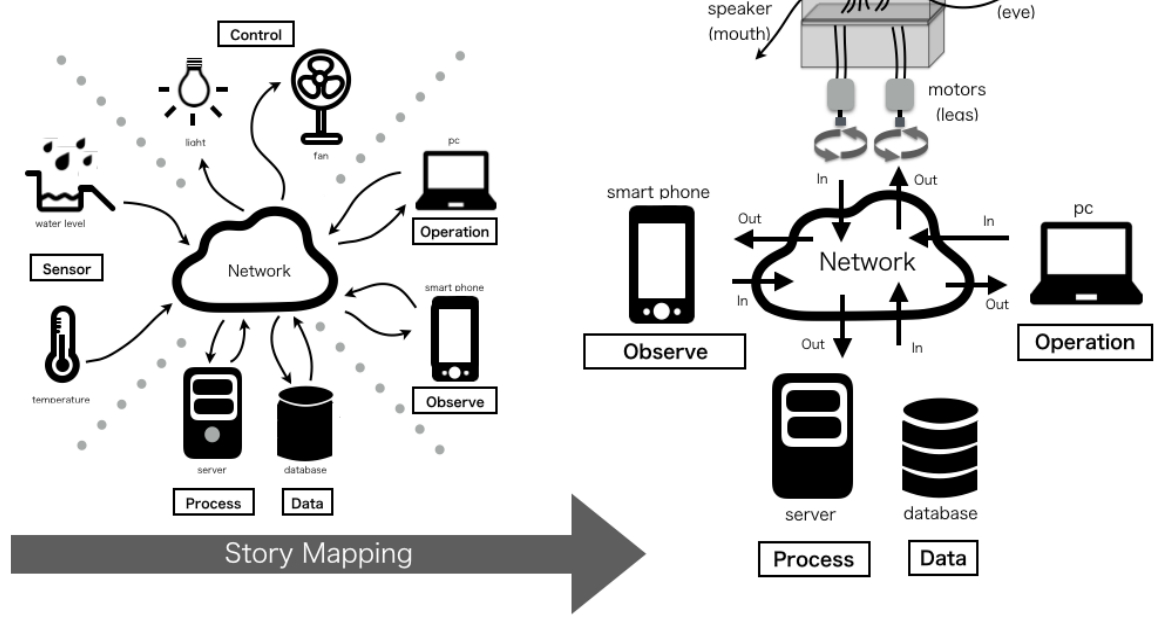

Fig. 1. Mapping Cyber-Physical System to an Educational Story (Seya et al., 2016)

\subsection{Comparison between the two different story making procedures}

We will call the type of a story created from a "past to present" as Type 1, and call the type of a story created from a "present to future" as Type 2. Table 2 shows the corresponding steps on the right and left so that the tasks on Type 1 and Type 2 procedures can be compared easily. In Table 2, the procedure of Type 1 [21] starts from Step 2 because there's no explicit equivalent of Step 1 of Type 2 in the procedure of Type 1. 
Table 2. Comparison of steps for making Type 1 and Type 2 stories

\begin{tabular}{|c|c|c|}
\hline & Past to Present (Type 1) & Present to Past (Type 2) \\
\hline Step 1 & $\begin{array}{l}\text { (There is no explicit statement which corre- } \\
\text { sponds to the Step } 1 \text { in Type 2) }\end{array}$ & $\begin{array}{l}\text { Grasp an overview of technical objectives in } \\
\text { the field }\end{array}$ \\
\hline Step 2 & Set a concrete learning goal & Set a concrete learning goal \\
\hline Step 3 & $\begin{array}{l}\text { Identify chronologically related main topics } \\
\text { which are necessary for accomplishing the } \\
\text { concrete learning goal }\end{array}$ & $\begin{array}{l}\text { Identify main topics which are necessary for } \\
\text { accomplishing the concrete learning goal, and } \\
\text { map them onto the parts of a story }\end{array}$ \\
\hline Step 4 & $\begin{array}{l}\text { Identify sub-topics which are necessary for } \\
\text { achieving the goals of main topics }\end{array}$ & $\begin{array}{l}\text { Identify sub-topics which are necessary for ac- } \\
\text { complishing the goals of main topics }\end{array}$ \\
\hline Step 5 & $\begin{array}{l}\text { Temporarily fix main topics and sub-topics } \\
\text { as lecture blocks }\end{array}$ & $\begin{array}{l}\text { Temporarily fix main topics and sub-topics as } \\
\text { lecture blocks }\end{array}$ \\
\hline Step 6 & $\begin{array}{l}\text { Implement main topics as chronologically or- } \\
\text { dered lecture blocks. Try to implement a sub- } \\
\text { topic inside a closely related main lecture } \\
\text { block unless the volume of the main lecture } \\
\text { block does not become too large }\end{array}$ & $\begin{array}{l}\text { Implement main topics. Try to implement the } \\
\text { main topics allowing the learners to see multi- } \\
\text { ple approaches and different levels of abstrac- } \\
\text { tion to solve the problems. Try to implement a } \\
\text { sub-topic inside a closely related main lecture } \\
\text { block unless the volume of the main lecture } \\
\text { block does not become too large }\end{array}$ \\
\hline Step 7 & $\begin{array}{l}\text { Implement lectures for large sub-topics as in- } \\
\text { dependent lecture blocks }\end{array}$ & $\begin{array}{l}\text { Implement lectures for large sub-topics as in- } \\
\text { dependent lecture blocks }\end{array}$ \\
\hline Step 8 & $\begin{array}{l}\text { Implement both core learning tasks for all } \\
\text { learners and advanced learning tasks for ad- } \\
\text { vanced learners in each lecture block. } \\
\text { Learning tasks should be broken down to } \\
\text { small learning blocks related to each other } \\
\text { to enable the agile method }\end{array}$ & $\begin{array}{l}\text { Implement both core learning tasks for all } \\
\text { learners and advanced learning tasks for ad- } \\
\text { vanced learners in each lecture block }\end{array}$ \\
\hline Step 9 & $\begin{array}{l}\text { Fix the lecture blocks if they are compatible } \\
\text { with administrative constraints. Go back to } \\
\text { Step } 3 \text { if it is necessary to meet the con- } \\
\text { straints }\end{array}$ & $\begin{array}{l}\text { Fix the lecture blocks if they are compatible } \\
\text { with administrative constraints. Go back to } \\
\text { Step } 3 \text { if it is necessary to meet the constraints }\end{array}$ \\
\hline Step 10 & $\begin{array}{l}\text { Place an introduction of the subject as the } \\
\text { first lecture block and explain the whole pic- } \\
\text { ture of the lecture in this block. And place an } \\
\text { outline session at the beginning of each lec- } \\
\text { ture block to explain the role of the lecture } \\
\text { block in relation to the previous topic }\end{array}$ & $\begin{array}{l}\text { Place an introduction of the subject as the first } \\
\text { lecture block and explain the whole picture of } \\
\text { the lecture in this block }\end{array}$ \\
\hline
\end{tabular}

\section{Evaluation}

We evaluated the difference in making stories between Type 1 and Type 2, which are described in Table 2. In each step described in Table 2, if there is a clear difference 
in the task description at the sentence level, we call such a difference, "Primary difference". In other words, if the descriptions on the right and left in Table 2 for a specific step are clearly different at the sentence level, we consider "there is a primary difference in the step". Comparative evaluation for the primary difference is self-explanatory because there is a clear difference at the sentence level in the descriptions on the left and right in Table 2. The evaluation results are summarized in Table 3.

There are additional descriptions on Step 8 and Step 10 in Type 1. However, we did not consider them as the sentence level difference but see them as the additional descriptions which are based on the second-order difference. The following section explains what the second-order difference is.

Table 3. Primary differences in how to make a story

\begin{tabular}{|c|c|c|c|}
\hline $\begin{array}{c}\text { Difference } \\
\text { ID }\end{array}$ & Step & $\begin{array}{c}\text { Presence } \\
\text { of } \\
\text { Primary } \\
\text { Difference }\end{array}$ & The primary difference between Type 1 and Type 2 \\
\hline \multirow[t]{2}{*}{ Diff1_1 } & Step 1 & YES & $\begin{array}{l}\text { Type } 1 \text { does not explicitly include this step to grasp an overview } \\
\text { of technical topics in the field. Since Type } 2 \text { aims at fostering } \\
\text { experts, it is necessary to grasp the whole picture at the first } \\
\text { stage, and to identify the technical topics that may be necessary } \\
\text { to work with unknown problems in the future, even though they } \\
\text { are not necessary at present }\end{array}$ \\
\hline & Step 2 & NO & \\
\hline \multirow[t]{3}{*}{ Diff1_2 } & Step 3 & YES & $\begin{array}{l}\text { When identifying technical main topics for Type } 1 \text {, the chrono- } \\
\text { logical or logical relationship among the topics is explicitly con- } \\
\text { sidered. For Type } 2 \text {, the coverage of technical topics is more im- } \\
\text { portant than the chronological or logical relationship among the } \\
\text { topics because the learners need to work with unknown problems } \\
\text { in the future }\end{array}$ \\
\hline & Step 4 & NO & \\
\hline & Step 5 & NO & \\
\hline \multirow[t]{5}{*}{ Diff1_3 } & Step 6 & YES & $\begin{array}{l}\text { The implementation of main topics is done with low abstraction } \\
\text { levels for Type } 1 \text {. High-level abstraction solutions are also con- } \\
\text { sidered for Type } 2 \text { because the learners need to learn multiple ap- } \\
\text { proaches to work with unknown problems in the future }\end{array}$ \\
\hline & Step 7 & NO & \\
\hline & Step 8 & NO & \\
\hline & Step 9 & NO & \\
\hline & Step 10 & NO & \\
\hline
\end{tabular}

\subsection{Second-order difference between Type 1 and Type2}

As the left and right descriptions on each procedural step in Table 2 are clearly different in Step 2, Step 4 and Step 5, it is obvious that there is a primary difference in 
these steps. On the other hand, Step 2, Step 4, Step 5, Step 7, Step 8, Step 9 and Step 10 shown in Table 2 are equivalent at the sentence level, and there is no primary difference in these steps. However, even though the same word is used in the sentence, the meaning changes depending on the context in which the word is used [24]. For example, the word "black" used as a color in some context and the same word "black" is used to indicate a "bad" sign in another context. Therefore, even if the descriptions in each step are the same at the sentence level, the meaning of descriptions may be different if the context is different. We define this level of difference as a second-order difference.

From the evaluation of primary differences in Table 3, we observe the common reason that makes such differences i.e. "whether the learners need to learn the technologies to work with unknown problems in the future." We take this common reason as the context between Type 1 and Type 2 because it is commonly found behind the comparison and it directly affects what needs to be done in each step on Type 1 and Type 2. Since the context defines the meaning of the words, the tasks on each step in Table 2 would be different even though the task descriptions are the same at the sentence level. For example, the task description, "Set a concrete learning goal", on Step 2 is the same for both Type 1 and Type 2, therefore, there is no primary difference between them. However, the goals for Type 1 and Type 2 are different because their contexts are different. While the goal for Type 1 is to guide the learners to its goal with a fixed single path, the goal for Type 2 is to provide multiple possible solutions to achieve its goal; this is a second-order difference, Diff2_1, found in Table 4. The other secondorder differences are also summarized in Table 4, which are found in Step 2, Step 7, Step 8, and Step 10.

Table 4. Second-order difference between Type 1 and Type2

\begin{tabular}{|c|c|l|}
\hline $\begin{array}{c}\text { Difference } \\
\text { ID }\end{array}$ & Step & \multicolumn{1}{|c|}{ Second-order difference between Type 1 and Type2 } \\
\hline Diff2_1 & Step 2 & $\begin{array}{l}\text { A fixed application is selected for Type 1. A generic application which allows } \\
\text { multiple ways of implementation is selected for Type 2 }\end{array}$ \\
\hline Diff2_2 & Step 7 & $\begin{array}{l}\text { The contents in the sub-topics for Type 1 should be minimal. The contents in the } \\
\text { sub-topics for Type 2 could be very rich }\end{array}$ \\
\hline Diff2_3 & Step 8 & $\begin{array}{l}\text { Learning tasks for Type 1 are intentionally designed to have a link with the } \\
\text { previous task while those for Type 2 are not related to each other }\end{array}$ \\
\hline Diff2_4 & Step 10 & $\begin{array}{l}\text { For Type 2, placement of an outline session at the beginning of each lecture } \\
\text { block is not necessary }\end{array}$ \\
\hline
\end{tabular}

\section{Discussion}

The first obvious difference between Type 1 and Type 2 is that the story creation process for Type 1 does not have an explicit step to grasp an overview of technical topics in the field. We could consider this as a manifestation of the fact that the need to completely investigate technical topics is not critically important for Type 1 because, it 
is not important for non-technical learners to cover as many solutions as possible to cope with unknown problems in the future.

For Type 1, the selected technical main topics have chronological or logical relationships among them; in other words, they are coherent. The connections between the topics are carefully designed so that the story becomes linear. The learning topics are technically simple and the number of them are minimal to achieve the goal (Figure 2). In Figure 2, we can observe that Type 1 is constructing a virtually simple linear story.

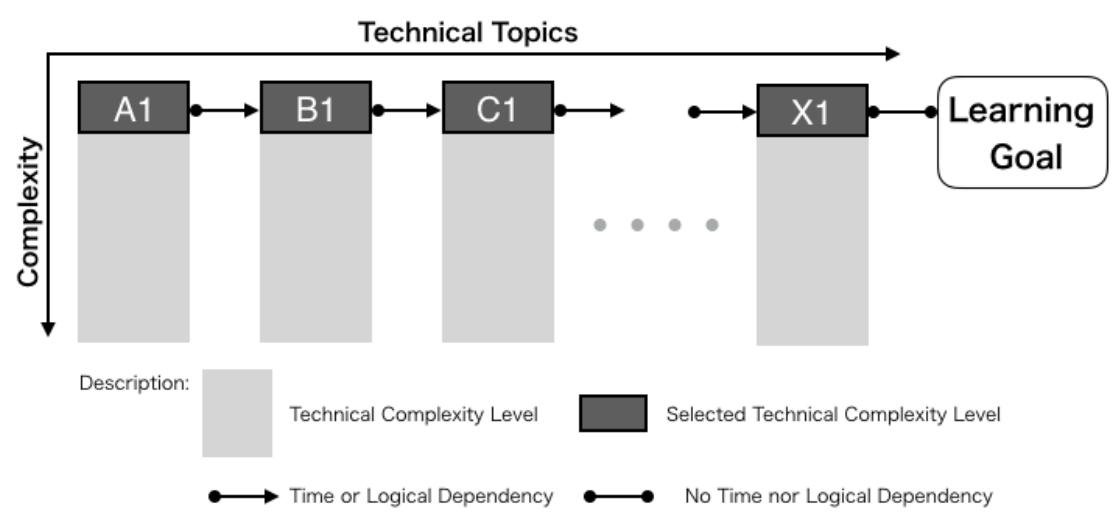

Fig. 2. Learning Topics in Type 1

On the other hand, the story creation process for Type 2 has an explicit step i.e. Step 1 to grasp an overview of technical topics in the field. The direct reason why this step is explicitly necessary for Type 2 is because it is a prerequisite for the work in Step 3 . For Type 2, not only the technical topics currently required but also the technical topics that may be required in the future are candidates for the main topics in Step 3, therefore it is necessary to look over all the important technical topics in the field.

In general, there are several solutions for solving a technical problem. Therefore, the learner who wants to be an engineer needs to be familiar with these multiple solutions. The learners will also need to learn how to approach a problem using different complexity and abstraction levels. For these reasons, Type 2 expands the choice of creating stories in three dimensions: technical topics, complexity, and alternative solutions (Figure 3). 


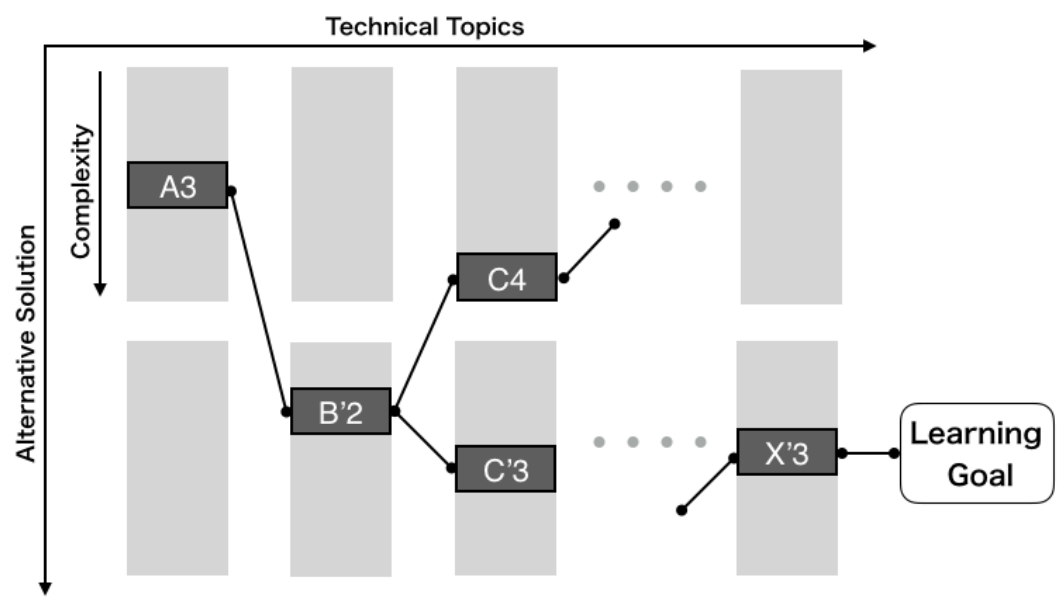

Fig. 3. Learning Topics in Type 2

For Type 2, the coverage of technical topics is more important than the chronological or logical relationship among the topics. That would make the learners feel uncomfortable because the technical topics tend to be unrelated to each other and difficult to find meaningful connections among the technical topics by the learners themselves. Indeed, the synthesis of what has been learned in each technical topic to achieve the learning goal is left to the learners in Type 2. For that reason, if the Type 2 story is used, it takes time for the learners to learn a wide range of technical topics in-depth and to synthesis what they have learned to achieve the goal. However, the learners who go through Type 2 story are more likely to be able to explore different solutions in the future when tackling unknown problems. On the other hand, Type 1 basically teaches only a minimum number of important solutions with a provided linear story. As a result, the learners who go through Type 1 story can save their learning time and see the important ideas clearly.

\subsection{Possibility of solving the issues of conversational programmers}

Conversational programmers are non-technical people who do not write programming code but want to learn how to program in order to be capable of participating in technical discussions and to increase the market value of themselves. Wang et al. studied conversational programmers' learning approaches and struggles and found the six common reasons why modern learning resources designed for technical people make them feel failures and opened the path for future research to find the solution for mitigating such failures [4]. Table 5 shows a list of six failures. 
Table 5. Six common reasons for feeling of failure among conversational programmers when using modern resources. (Wang et al., 2018)

\begin{tabular}{|c|l|l|}
\hline $\begin{array}{c}\text { Issue } \\
\text { ID }\end{array}$ & $\begin{array}{l}\text { Reasons for Feelings } \\
\text { of Failure }\end{array}$ & \multicolumn{1}{|c|}{ Description } \\
\hline i01 & Takes too much time & $\begin{array}{l}\text { Investing in learning programming ended up requiring more time than } \\
\text { what participants wanted to devote given their busy schedules }\end{array}$ \\
\hline i02 & $\begin{array}{l}\text { Too much focus on } \\
\text { syntax and logic }\end{array}$ & $\begin{array}{l}\text { Most of the resources focused on programming syntax and logic which } \\
\text { did not directly help participants with their technical conversation }\end{array}$ \\
\hline i03 & $\begin{array}{l}\text { Explanations are not } \\
\text { relevant }\end{array}$ & $\begin{array}{l}\text { The conceptual and application-related explanations desired by the par- } \\
\text { ticipants were not always relevant nor available in the learning resources }\end{array}$ \\
\hline i04 & $\begin{array}{l}\text { Difficult to assess the } \\
\text { content's reliability }\end{array}$ & $\begin{array}{l}\text { Participants did not feel confident enough to assess whether a given re- } \\
\text { source contained accurate and reliable content }\end{array}$ \\
\hline i05 & $\begin{array}{l}\text { Feelings of social iso- } \\
\text { lation }\end{array}$ & $\begin{array}{l}\text { Resources and learning environments that target CS students or profes- } \\
\text { sional programmers often created feelings of social isolation among par- } \\
\text { ticipants }\end{array}$ \\
\hline i06 & $\begin{array}{l}\text { Easy to forget details } \\
\text { It was easy for participants to forget programming definitions and de- } \\
\text { tails because they did not apply what they learned directly on-the-job }\end{array}$ \\
\hline
\end{tabular}

We discuss a possible approach to solve conversational programmers' issues by leveraging our findings about the differences between Type 1 and Type 2 appeared as primary differences and second-order differences.

While Type 1 story only expands to a single chronological or logical direction as it is described in Figure 2, Type 2 story not only expands to that direction but also to the alternative solution and complexity direction as it is described in Figure 3. This situation is depicted in Figure 4. In Figure 4, Selection 1 is the operation to reduce the number of solution alternatives and Selection 2 is the operation to reduce the complexity of each technical topic. A connection is an operation to set the context between the technical topics to connect them chronologically or logically. If the connections are carefully designed, the learners can follow the learning path without needing to find a clear path to achieve the learning goal by themselves.

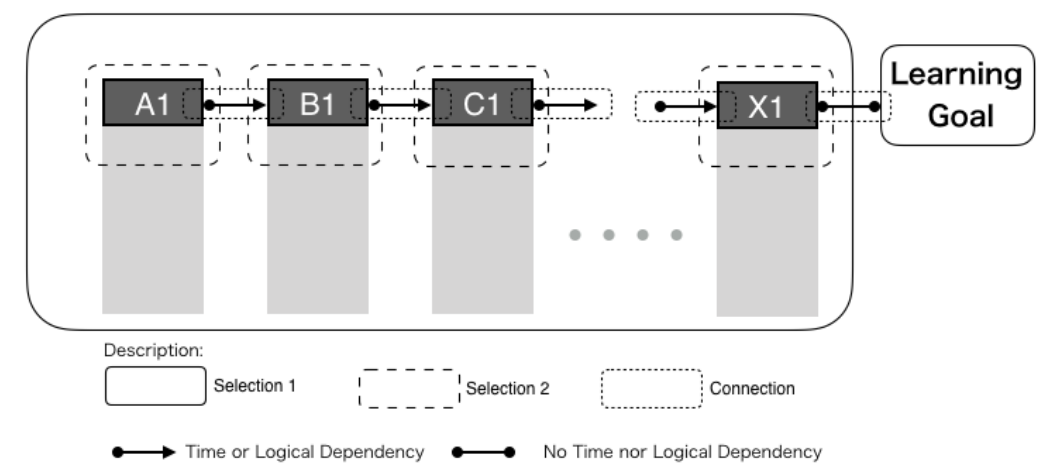

Fig. 4. Operations in Type 1 
Table 6 shows how each operation in Type 1 is associated with the conversational programmers' issues as the solution. It is O-marked where the operation can be a solution to the issue.

Table 6. Operation as a solution to the issues

\begin{tabular}{|l|l|l|l|l|l|l|l|}
\hline \multirow{2}{*}{ Operation } & \multicolumn{2}{|c|}{ Description } & \multicolumn{5}{c|}{ Issue ID } \\
\cline { 3 - 9 } & & $\mathbf{i 0 1}$ & $\mathbf{i 0 2}$ & $\mathbf{i 0 3}$ & $\mathbf{i 0 4}$ & $\mathbf{i 0 5}$ & $\mathbf{i 0 6}$ \\
\hline Selection 1 & Reduce the choice of multiple solutions & O & & & & O & \\
\hline Selection 2 & Reduce complexity and abstraction choices & O & O & & O & O & O \\
\hline Connection & Organize chronological or logical stories & & & O & & O & O \\
\hline
\end{tabular}

Following are the list of operations and issue IDs with the reasons why they are Omarked in Table 6. The id in the parentheses is the Issue ID in Table 6.

Operation: Selection 1

- (i01) Time is reduced by the limited learning scope.

- (i05) Because the learning scope is limited, the learners can feel that they can participate in discussions.

\section{Operation: Selection 2}

- (i01) By limiting the learning tasks, the learning scope is further reduced than Selection 1.

- (i02) The learners only learn the syntax and logic they need to achieve the learning goal.

- (i04) Since the scope of each learning topic is limited and typical, the credibility of the learning contents can be investigated by the learners.

- (i05) Since the scope of each learning topic is limited, learners are less likely to get lost in the discussions.

- (i06) Lectures are designed to teach only the minimum necessary to achieve a learning goal, so there are fewer things to remember to complete a lecture.

\section{Operation: Connection}

- (i03) Since the learners are taught only the minimum necessary to achieve the learning goal, they feel everything they learn is relevant to achieve the goal.

- (i05) Since the relationship between the learning topics is structured, and the alternative links are eliminated for the sake of simplicity, the learners are less prone to get lost in the discussions.

- (i06) The learning topics are not separated, but they make up a single story, making them easy to remember for the learners. 
By the way, the difference (Difference ID) between Type 1 and Type 2 that was revealed from the comparison of this study affects the three operations of "Select 1", "Select 2", and "Connect". Following is the reason why those operations are affected by the difference between Type 1 and Type 2 from the Type 1 perspective:

\section{Diff1_1:}

- Selection 1: The most typical and necessary minimum technical elements will be selected.

- Connection: A chronological or logical connection is envisaged.

\section{Diff1_2:}

- Connection: Chronologically or logically related main topics are selected.

\section{Diff1_3:}

- Selection 2: Learning tasks with a low level of complexity and abstraction are selected.

\section{Diff2_1:}

- Connection: The goal is achieved with a chronologically or logically connected structure.

\section{Diff2_2:}

- Selection 2: Select the minimum learning tasks required for the subtopic lecture.

\section{Diff2 3:}

- Selection 2: In the implementation of the exercise, the minimum necessary exercises are implemented as a core exercise group, and for learners who are a little more advanced, the extended exercises relevant to the core exercises are provided.

\section{Diff2_4:}

- Connection: The first lecture is a chronological overview of the subject

Therefore, the difference between Type 1 and Type 2 affects the problem of the conversational programmer as a result of affecting the three operations "Selection 1", "Selection 2", and "Connection". For the above reasons, the more prominent these differences are, that is, the more prominent the Type 1 features, the higher the probability that the problem of the conversational programmer can be solved. Table 7 summarizes which operations are affected by the difference between Type 1 and Type 2, and as a result, which conversational programmer's problem (Issue ID) is likely to be solved. 
Table 7. Effect of Differences in how stories are created upon the conversational programmers' problems

\begin{tabular}{|l|c|c|c|c|c|c|c|c|c|}
\hline $\begin{array}{c}\text { Difference } \\
\text { ID }\end{array}$ & Selection 1 & Selection 2 & Connection & \multicolumn{5}{|c|}{ Issue ID } \\
\hline & & & & $i 01$ & $\boldsymbol{i 0 2}$ & $\boldsymbol{i 0 3}$ & $\boldsymbol{i 0 4}$ & $\boldsymbol{i 0 5}$ & $\boldsymbol{i 0 6}$ \\
\hline Diff1_1 & O & & O & O & & O & & O & O \\
\hline Diff1_2 & & & O & & & O & & O & O \\
\hline Diff1_3 & & O & & O & O & & O & O & O \\
\hline Diff2_1 & & & O & & & O & & O & O \\
\hline Diff2_2 & & O & & O & O & & O & O & O \\
\hline Diff2_3 & & O & & O & O & & O & O & O \\
\hline Diff2_4 & & & O & & & O & & O & O \\
\hline
\end{tabular}

\subsection{Comparison of Type1 and Type 2 from multiple viewpoints}

Table 8 shows the relative and general differences between Type 1 and Type 2 from multiple viewpoints. The viewpoints are listed at the left end of Table 8 , and the reasons are shown at the right end. This comparison is relative and general but provides additional insights over the difference of the story types because it leads us to think the difference in a larger context than a teaching material context. Moreover, Table 8 could be used as a general guide for selecting an appropriate story type in achieving a given educational goal.

Table 8. Comparison of Type1 and Type2 from multiple viewpoints

\begin{tabular}{|l|l|l|l|}
\hline \multicolumn{1}{|c|}{ Viewpoint } & Past to Present & \multicolumn{1}{|c|}{$\begin{array}{c}\text { Present to } \\
\text { Future }\end{array}$} & Reason \\
\hline Learning Time & short & long & $\begin{array}{l}\text { Diff1_1, Diff1_3, Diff2_2, } \\
\text { Diff2_3 }\end{array}$ \\
\hline Story clarity & clear & unclear & Diff1_1, Diff1_2, Diff2_1 \\
\hline Ease of remembering & easy & difficult & $\begin{array}{l}\text { Diff1_2, Diff1_3, Diff2_2, } \\
\text { Diff2_3 }\end{array}$ \\
\hline Number of technical topics & few & many & Diff1_1 \\
\hline Technical depth & shallow & deep & Diff1_3 \\
\hline $\begin{array}{l}\text { Flexibility for unknown chal- } \\
\text { lenges }\end{array}$ & small & large & Diff1_1, Diff1_3 \\
\hline Ease of making teaching materials & difficult & easy & Diff1_2, Diff2_3 \\
\hline Versatility of teaching materials & small & large & Diff1_2, Diff1_3, Diff2_3 \\
\hline Dependence on learner experience & large & small & Diff1_2, Diff1_3 \\
\hline
\end{tabular}

\subsection{Limitations and future research topics}

In this study, we compared a story-building method which is effective for non-technical people created from a "past to present" perspective with a story-building method which is effective for technical people created from a "present to future" perspective and then evaluated the difference between the two story-building methods. However, we did not evaluate if the story-building method for non-technical people also works for technical people, nor the story-building method for technical people works for nontechnical people (Table 9). It would be worth verifying the effectiveness of the stories 
under the different groups of people. Also, investigating the influence of the instructor's skill on the learning outcomes would be useful to make the teaching materials not relying on the instructor's skill.

We know the fact that the story with chronologically or logically connected learning topics reduced the cognitive workload for non-technical people when they learn complex technology [9] and now we identified the characteristics of such a story in this study, but we do not know why it works. It an open research topic to find a hypothesis which can explain the reason why it works. We also know that it has been revealed that there are five problems with a story created from a "present to future" perspective when it is provided completely online [22]. It is worth researching the solutions for these problems by utilizing the foundlings in this study. In addition, since new technologies can change rapidly and drastically, learners would be put in a situation where they have to advance their learning in the absence of teachers. Research on how we can apply the features of story-building methods in a learning environment where learners teach each other online or offline would contribute to making the education scalable.

Table 9. Limitations of the coverage of the study

\begin{tabular}{|l|l|l|}
\hline & \multicolumn{1}{|c|}{ Past to Present } & Present to Future \\
\hline Non-technical People & $\mathrm{O}$ & $\mathrm{X}$ \\
\hline Technical People & $\mathrm{X}$ & $\mathrm{O}$ \\
\hline
\end{tabular}

\section{Conclusion}

The novelty of this research is that the proposal of perspectives that reveal the differences in the stories used for emerging technology education and that we have identified the features of one of the effective stories suited for non-technical adult learners. We classified the story for non-technical people as a story created from a "past to present" perspective and the story for technical people as a story created from a "present to future" perspective and compared them in terms of story-building methods.

The story created from "present to future" perspective" has a large learning space and the learners are expected to acquire new knowledge for the purpose of being capable of dealing with unknown problems in the future. Also, the technical people are expected to find the relationships among the learning topics by themselves to achieve the learning goal.

On the other hand, the story created from a "past to present" perspective provides carefully designed connections between the learning topics in a way they make the story so linear that the learners clearly see the path to the learning goal. It indicates that it is not a small step instructional strategy which makes the story easy to understand, but it is theses carefully designed connections that make the learning materials linear and easy to understand. The drawback of this approach is that finding such connections could be time-consuming for the people who prepare solid learning materials.

Since the adult learners could take advantage of their experience to work with learning topics, if a connection between the learning topics is properly provided, they could 
go through the learning path within a short time. It indicates that a story created from a "past to present" perspective may be more effective for adults than children.

In addition, it is suggested that the more the features of the Type 1 story are emphasized in a way the difference between the two stories revealed in this study becomes clearer, the more likely it is to solve the problem [4] of adult learners called conversational programmers.

A future research topic is to understand the reason why a story created from a "past to present" perspective reduces the cognitive workload for non-technical people when they learn complex technology. Other research topics include research on how to solve problems that occur when a story created from a "present to future" perspective is provided online, and whether the two story-building methods discussed in this study work effectively even in a learning environment where the learners teach each other.

\section{$8 \quad$ References}

[1]World intellectual property organization, WIPO Technology Trends 2019, Artificial intelligence. 2019.

[2]P. K. Chilana et al., "Perceptions of non-CS majors in intro programming: The rise of the conversational programmer," in 2015 IEEE Symposium on Visual Languages and HumanCentric Computing (VL/HCC), Atlanta, GA, 2015, pp. 251-259. https://doi.org/10.1109/ vlhcc.2015.7357224

[3]P. K. Chilana, R. Singh, and P. J. Guo, "Understanding Conversational Programmers: A Perspective from the Software Industry," in Proceedings of the 2016 CHI Conference on Human Factors in Computing Systems - CHI '16, Santa Clara, California, USA, 2016, pp. 1462-1472. https://doi.org/10.1145/2858036.2858323

[4]A. Y. Wang, R. Mitts, P. J. Guo, and P. K. Chilana, "Mismatch of Expectations: How Modern Learning Resources Fail Conversational Programmers," in Proceedings of the 2018 CHI Conference on Human Factors in Computing Systems, New York, NY, USA, 2018, pp. 511:1-511:13. https://doi.org/10.1145/3173574.3174085

[5]“AI for Everyone," deeplearning.ai. [Online]. Available: https://www.deeplearning.ai/. [Accessed: 06-Sep-2019].

[6]"Machine Learning for Business Professionals," Google Cloud. [Online]. Available: https://cloud.google.com/training/courses/machine-learning-business-professionals. [Accessed: 04-Sep-2019]. https://doi.org/10.1007/978-1-4842-4470-8_41

[7]"MIT Sloan Artificial Intelligence: Implications for Business Strategy online program." [Online]. Available: https://executive-education.mit.edu/mit-artificial-intelligence-onlineshort-course-lf-lang/?\&ef_id=c:376794583857_d:c_n:g_ti:aud-733905065437:kwd392017031683_p:_k:\%2Bmit\%20\%2Bai_m:b_a:76948906717\&gclid=EAIaIQobChMImuDCgMm25AIVU6WWCh1BUwAAEAAYASAAEgLCcPD BwE. [Accessed: 04-Sep-2019].

[8]K. Seya and S. Shirasaka, "Building Robots and Story-Based Learning to Teach CyberPhysical Systems Effectively to Any Class of Audiences ranging from Elementary School Students to University Graduates," INCOSE International Symposium, vol. 26, no. s1, pp. 124-136, 2016. https://doi.org/10.1002/j.2334-5837.2016.00319.x 
[9]K. Seya, N. Kobayashi, and S. Shirasaka, "Effectiveness of Story-based Visual and Agile Teaching Method for Non-technical Adult Learners who want to understand Artificial Intelligence," presented at the 8th International Congress on Advanced Applied Informatics, Japan, 2019.

[10]G. Bateson, "Multiple Versions of the World," in Mind and nature: a necessary unity, Cresskill, NJ: Hampton Press, Inc., 2002, p. pp.61-82.

[11]P. A. Ertmer and T. J. Newby, "Behaviorism, Cognitivism, Constructivism," in Foundations of Learning and Instructional Design Technology, 2017.

[12]M. Knowles, “The Adult Learner: A Neglected Species,” Apr. 1973.

[13]V. C. Bryan and K. Steinke, "Adult Learning in a Digital Age: Effective Use of Technologies for Adult Learners."

[14]O. V. Galustyan, Y. V. Borovikova, N. P. Polivaeva, K. R. Bakhtiyor, and G. P. Zhirkova, "E-learning within the Field of Andragogy," International Journal of Emerging Technologies in Learning (iJET), vol. 14, no. 09, pp. 148-156, May 2019. https://doi.org/10.3991/ ijet.v14i09.10020

[15]G. Bisovsky and S. Schaffert, "Learning and Teaching With E-Portfolios: Experiences in and Challenges for Adult Education," International Journal of Emerging Technologies in Learning (iJET), vol. 4, no. 1, pp. 13-15, Feb. 2009. https://doi.org/10.3991/ijet.v4i1.822

[16]J. Pauschenwein and A. Sfiri, "Adult Learner's Motivation for the Use of MicroBlogging During Online Training Courses," International Journal of Emerging Technologies in Learning (iJET), vol. 5, no. 1, pp. 22-25, Feb. 2010. https://doi.org/10.3991/ijet.v5i1.1041

[17]A. V. Didenko, N. Aksenova, and A. V. Loginova, "The Choice of Effective Methods and Approaches to the Design of an Online Course," International Journal of Emerging Technologies in Learning (iJET), vol. 11, no. 04, pp. 150-152, Apr. 2016. https://doi.org/10. 3991/ijet.v11i04.5270

[18]Z. Turan, Z. Avinc, K. Kara, and Y. Goktas, "Gamification and Education: Achievements, Cognitive Loads, and Views of Students," International Journal of Emerging Technologies in Learning (iJET), vol. 11, no. 07, pp. 64-69, Jul. 2016. https://doi.org/10.3991/ijet.v11 $\underline{\mathrm{i} 07.5455}$

[19]K. Madhusudhana, "The Cognitive Dimension and Course Content Modeling: An Ontological Approach," International Journal of Emerging Technologies in Learning (iJET), vol. 12, no. 05, pp. 181-188, May 2017. https://doi.org/10.3991/ijet.v12i05.6854

[20]P. Charters, M. J. Lee, A. J. Ko, and D. Loksa, "Challenging stereotypes and changing attitudes: the effect of a brief programming encounter on adults' attitudes toward programming," in Proceedings of the 45th ACM technical symposium on Computer science education - SIGCSE '14, Atlanta, Georgia, USA, 2014, pp. 653-658. https://doi.org/10. $\underline{1145 / 2538862.2538938}$

[21]K. Seya, N. Kobayashi, and S. Shirasaka, "Method of Creating Story-based Lectures from a Past-to-present Perspective that Helps Non- Technical Adult Learners Understand AI," Review of Integrative Business and Economics Research, vol. 9, no. 1, pp. 16-45, 2019.

[22]K. Seya, T. Okatani, Y. Matsuo, N. Kobayashi, and S. Shirasaka, "Identifying Issues for Learners in Completing Online Courses on Machine Learning and Deep Learning: Five Issues Found in a Fully Automated Learning Environment for the Purpose of Scalable AI Education," Review of Integrative Business and Economics Research, vol. 9, no. 3, pp. 3554, 2019.

[23]M. D. P. Requejo, "The Role of Context in Word Meaning Construction: A Case Study," 1, vol. 7, no. 1, pp. 169-179, 2007. 


\section{$9 \quad$ Authors}

Keisuke Seya is an Adjunct Professor at Shizenkan University and a lecturer at Keio University and belongs to a Ph.D. program at the Department of Graduate School of System Design and Management of Keio University in Kanagawa, Japan.

Nobuyuki Kobayashi received his Ph.D. in System Engineering from Keio University and belongs to the System Design and Management Research Institute of Graduate School of System Design and Management at Keio University in Kanagawa, Japan.

Seiko Shirasaka is a Professor at the Department of Graduate School of System Design and Management of Keio University in Kanagawa, Japan.

Article submitted 2019-09-08. Resubmitted 2019-10-21. Final acceptance 2019-10-18. Final version published as submitted by the authors 